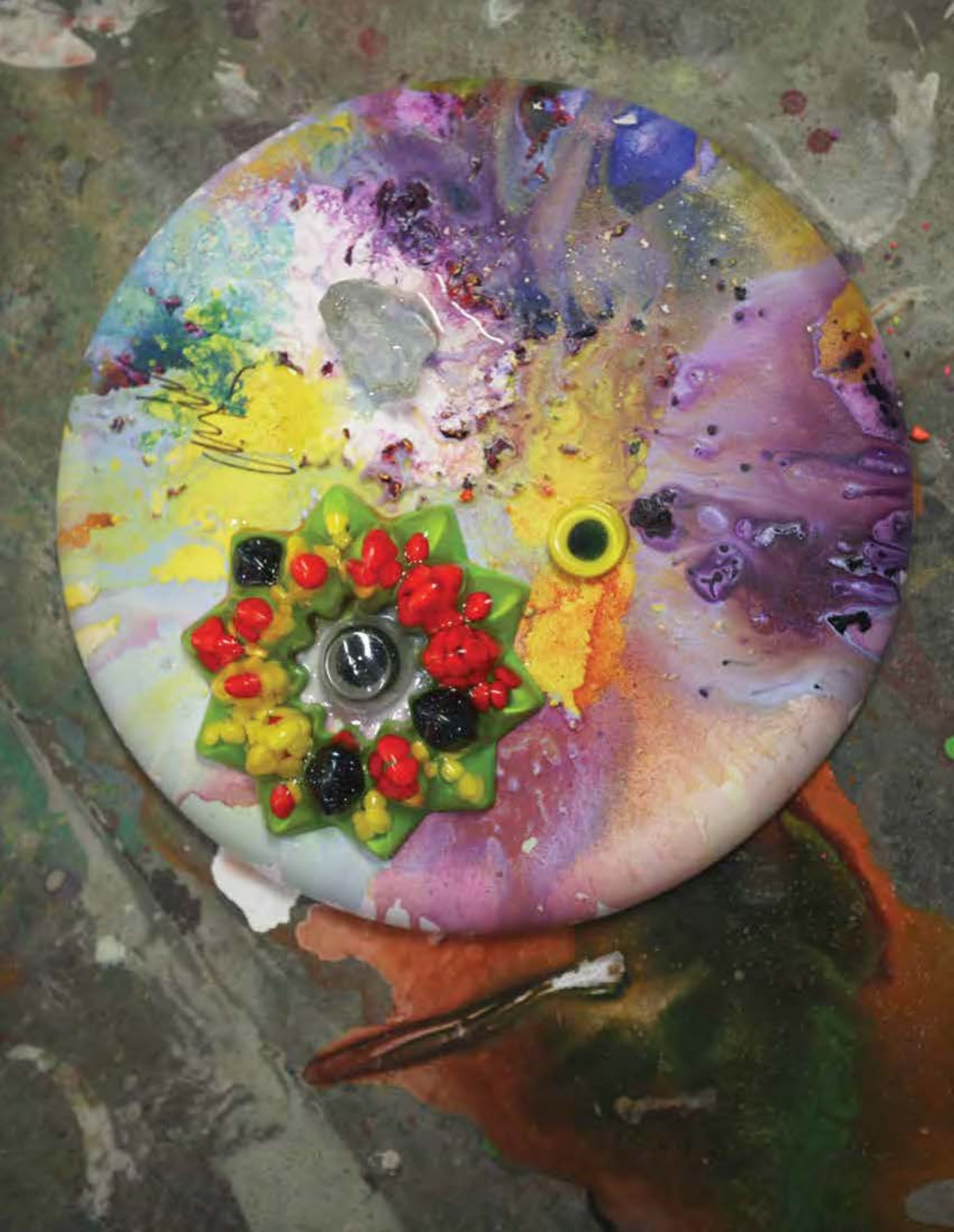




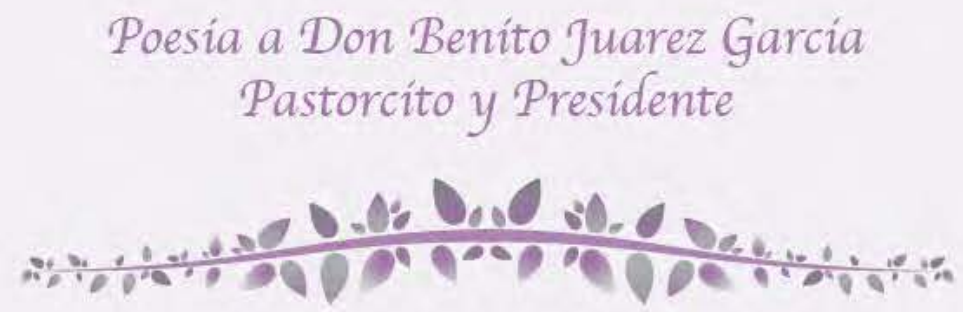

En casa lejana de barro y de paja, el niño Benito nació una mañana. Vestido de manta y jerga de lana soñaba mirando el agua encantada. Tocaba su flauta, su flauta tocaba y las ovejitas Galaban, Galaban. $Y$ aquel indiecíto, calmando sus ansias valiente se marchacon rumbo a Oaxaca. $Y$ fue licenciado, llegó a Presidente. ¿Que viva ef gran Juárez ! ¡Que vivan sus leyes! 


\title{
Centroamericanos en el Sur-Sureste de México. La Construcción de una Región Migratoria
}

\author{
VIRGINIA GUADALUPE REYES DE LA CRUZ \\ Recibido 10.05.16 / Aprobado 11.08.16
}

RESUMEN. El presente estudio es un esbozo de la migración centroamericana en Oaxaca-México, considerando el periodo 2009 2014 para el nivel nacional y el periodo 2012-2015 para el nivel local, se hizo uso de datos producidos principalmente por la Red de Documentación de las Organizaciones Defensoras de Migrantes (REDODEM), y por la Encuesta sobre Migración en la Frontera Sur de México, los cuales muestran el comportamiento de este fenómeno en la entidad sureña de México, las circunstancias que enfrentan y cómo las afrontan, convirtiéndose ésta en un lugar de tránsito pero también de residencia temporal y, en algunos casos, definitiva bajo la modalidad de migración indocumentada. Oaxaca tiene una característica principal, pues a la vez que es un estado expulsor de migrantes, es una zona receptora de migración centroamericana. Sus condiciones socioeconómicas y políticas lo ubican como un lugar de marginación y pobreza, con regiones donde el índice de violencia es alto y donde muchas veces, los migrantes de Centroamérica tienen que transitar o vivir, constituyendo su región migratoria.

Palabras clave: Migración de tránsito, Centroamérica, región migratoria, inmigración.

ABSTRACT. The present study is an introduction about migration of central-americans in the state Oaxaca-Mexico, based on 20092014 period for a national level and 2012-2015 period, for a the State level records, using data from REDODEM (Migrant Defenders Organizations Documentation Web by the Acronym in Spanish) and Mexican South Border Migration Survey, these sources shows the migration phenomenom in this southern state, what kind of circumstances and challenges are faced by migrants, how they manage them, and how Oaxaca is becoming a transitive place but also a temporal residence, and in some cases, definitive, under a undocumented/ilegal migration status. Oaxaca is a place of transit and temporary or permanent residence of migrants coming from Central America; i.e. people remains in the mode of undocumented migration. The socio-economic and political conditions of the State indicates that it is an immigration region with high levels of marginalization, poverty and violence. These conditions constitutes as migrant region.

Keywords: Transitive migration, Central America, migrant region, inmigration.

\section{Introducción}

La migración internacional es un fenómeno de antaño y complejo; tiene diversas aristas y responde a un sinfín de necesidades, tanto del país expulsor como del receptor. Esta categoría de análisis tiene dos clasificaciones: la migración internacional regular y la migración internacional irregular. El presente artículo aborda las problemáticas que enfrenta la comunidad migrante centroamericana irregular a su llegada a las regiones en las que tiene que instalarse por un tiempo para poder continuar su marcha hacia el norte del continente. La intención de los migrantes provenientes del sur de América y el Caribe es atravesar la frontera del norte de México e instalarse en algún lugar de Estados Unidos de América; de esta manera, el país mexicano se convierte en un país de tránsito, pero particularmente tiene regiones que se clasifican como zonas de tránsito, constituidas por las entidades sureñas.
El objetivo del trabajo es reconocer las situaciones que enfrentan los migrantes centroamericanos al llegar a tierras oaxaqueñas, y conformar -sin concebirlo- una región migratoria en tránsito. El artículo se divide en cuatro apartados; 1) Contexto, donde se expone qué es Centroamérica y por qué se constituye como una región expulsora de migrantes, 2) Migración centroamericana en México, presenta un análisis estadístico del flujo migratorio centroamericano, con datos desde el 2004 hasta el 2016, referentes al lugar de nacimiento, su situación legal en el país, el nivel de instrucción y la actividad económica en que se desempeñan, 3) De Centroamérica a Oaxaca, ¿Migración de tránsito? Es un análisis de los migrantes centroamericanos en el estado, dónde se refugian al llegar a tierra mexicana, dónde laboran, en fin, quiénes son, qué oportunidades tienen y qué desean, 4) Conclusiones.

1. Doctora en Educación con estudios de maestría en Sociología con atención al Desarrollo Regional y especialidades en investigación con perspectiva de género y políticas públicas. Miembro del SNI, nivel I y perfil PRODEP. Líder del Cuerpo Académico Estudios sobre la Sociedad Rural del Instituto de Investigaciones Sociológicas de la Universidad Autónoma Benito Juárez de Oaxaca (IISUABJO), su principal línea de investigación es Sociedades Rurales y Globalización dentro de sus trabajos destacan los estudios de movilidad, flujos migratorios y políticas públicas; Género y Educación. Contacto. Correo electrónico: rvicky52@hotmail.com. Teléfono del IISUABJO: 9515166019 y 9515143759 ext. 102. 


\section{Metodologia}

El presente trabajo pretende mostrar una radiografia de la situación de vulnerabilidad de los migrantes centroamericanos en Oaxaca -recientemente llamada por la Red de Documentación de las Organizaciones Defensoras de Migrantes (REDODEM), "una crisis humanitaria internacional" $(2015)^{2}$, abarcando el periodo 2009-2014 para ilustrar cómo se encuentra el nivel nacional y el 20122015, para el caso concreto de Oaxaca.

Para tal efecto, se utilizó la investigación documental: el Informe Estadístico sobre las características de los transmigrantes centroamericanos, que elabora la REDODEM; la Encuesta sobre Migración en la Frontera Sur de México, elaborada por el Colegio de la Frontera Norte, el Consejo Nacional de Población (CONAPO), la Secretaria del Trabajo y Previsión Social (STPS) y; datos que proporcionan dos albergues de atención al migrante que funcionan en el Estado de Oaxaca: "Hermanos en el Camino, ubicado en Ciudad Ixtepec y, el "Centro de Orientación al Migrante de Oaxaca"; así como un pequeño seguimiento hemerográfico digital.

En este sentido, la información que se presenta proviene de fuentes secundarias, con el fin de tener una primera aproximación al fenómeno en cuestión, debido a que la migración de centroamericanos ha sido poco estudiada en Oaxaca.

Los datos reflejan la situación del migrante centroamericano en el estado y los problemas por los cuales atraviesa en su estancia en dos ciudades del mismo, Ciudad Ixtepec y Oaxaca de Juárez.

\section{Discusión de resultados}

\subsection{Contexto centroamericano}

La región centroamericana está comprendida por los países de Guatemala, Belice, Honduras, El Salvador, Nicaragua, Costa Rica y Panamá; "como región puede ser definida como una entidad territorial, conformada por estados y sociedades que comparten lazos históricos, sociales, culturales, étnicos y lingüístico con debilitamiento de la cohesión intrarregional y un enclipsamiento de su identidad político institucional por el regionalismo de libre mercado derivado de la estrategia de bloques comandada por Estados Unidos" (Morales, 2008).

Centroamérica ha sufrido diversos cambios sociopoliticos a lo largo de su historia. Su régimen antiguo de dominación y su vida política -dictaduras, guerras civiles, guardias nacionales, guerrillas-, gradualmente se fue convirtiendo en una democracia con algunos elementos autoritarios.

Centroamérica ha presentado cambios políticos, pero también ha sido una región que se abrió a la inmigración de miles de personas provenientes de otros continentes y que, a partir de la década de los 60 el fenómeno se invierte y se vuelve zona de expulsores (Figura $\mathrm{N}^{\circ} 1$ ).

\section{Figura $\mathrm{N}^{0} 1$. Migración centroamericana en el tiempo}

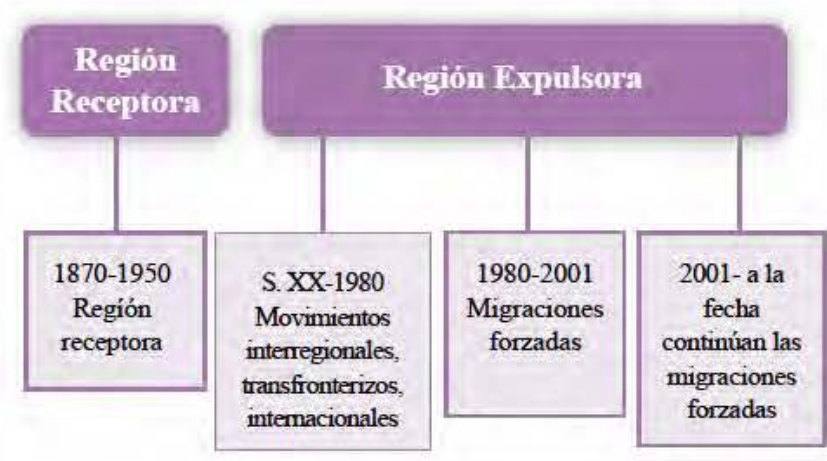

Fuente: Elaboración propia con base en Escobar (2008)

Como lo muestra la Figura $\mathrm{N}^{\circ} 1$, el estudio de la región migratoria centroamericana se divide en dos fases históricas: como una región receptora y como la región expulsora en la cual se ha convertido desde mediados del Siglo XX. Carolina Escobar (2008), distingue estos momentos de la siguiente manera:

De 1870 a 1950 , fue la revolución capitalista la que provocó que los paises europeos se posicionaran como regiones expulsoras, al afectar este sistema económico a muchas familias que ya no veían bien redituado su trabajo en aquel continente. Anterior a este periodo se puede notar la llegada de afrodescendientes a la zona centroamericana, cuando se establecieron en calidad de esclavos. Desde la segunda mitad del siglo XIX, son numerosas las familias que se desplazaban desde Guatemala a la frontera sur de México para trabajar temporalmente en el cultivo de la caña de azúcar, café y algodón. La mayoría de estos trabajadores provenían de comunidades indigenas. Este tipo de migración de carácter temporal agrícola continúa en la actualidad en las fincas del sur de México (ONU, 2000).

La migración en este período empezó a desplazarse también de las zonas de la agricultura a la zona urbana; en el caso de México, se presentó una migración hacia Tabasco por ser una zona petrolera, situándolo como un polo de atracción para toda la región Sur-Sureste, principalmente en 
sus municipios con mayor desarrollo petrolero. Cabe señalar que en estas labores, tuvo más presencia el varón; mientras que la mujer centroamericana se empezó a concentrar en los bares y cabaret de la ciudad.

En el segundo momento de las migraciones centroamericanas, hubo movimientos intrarregionales, transfronterizos e internacionales, provocados por los conflictos armados en Centroamérica. En este momento, el sur de México, Costa Rica y Honduras fueron los receptores de migrantes de Guatemala, El Salvador y Nicaragua.

La migración forzada comienza a suscitarse por factores sociopolíticos, económicos y ambientales. "Al inicio de los noventa, no obstante haber terminado los conflictos armados en Centroamérica, la emigración continuó creciendo, impulsada por la precariedad laboral, la pobreza, la violencia y, en algunos países, la inestabilidad política" (ITAM, 2014).

De 2001 a la actualidad, los desplazamientos son provocados por la presencia de bandas delictivas organizadas internacionalmente, entre ellas, la mara Salvatrucha. Además, continúa la desatención gubernamental de esos países a los diversos sectores de su población.

Las dinámicas poblacionales que ha vivido la región centroamericana, están intrínsecamente vinculadas a su proceso histórico, político y social, en el cual la migración se ha convertido en una válvula de escape para todos aquellos que han decidido cambiar su modo de vida y para aquellos que han buscado extender sus mecanismos de violencia a otros ámbitos.

La migración no sólo impacta a los que se desplazan a otros lugares, sino que también tiene su implicación con los nuevos territorios a los cuales llegan los grupos de migrantes y que les permite adentrarse en nuevos procesos culturales que modifican prácticas sociales, que impactan tanto en los sectores locales como en los más amplios y complejos. Por ello a continuación se abordará cómo se presenta la migración centroamericana en México.

\subsection{Migración centroamericana en México}

¿Qué es la migración centroamericana? Un movimiento trasnacional. Se refiere al tránsito o establecimiento de los centroamericanos en algún lugar de México, con el propósito de cruzar la frontera de los Estados Unidos de América, mismo que comparten con los mexicanos que también se encuentran en condiciones desfavorables tanto sociales como económicas y políticas y que tienen la intención de migrar.

De acuerdo con los cambios tecnológicos y de condición de estadía, hoy se podría decir que los migrantes no se van del todo sino que llevan en su cuerpo toda una carga emocional de pertenencia que migra con ellos y los hace presentarse en un lugar con todo lo que son y sin dejar de serlo, con sus características que los hacen vulnerables en los lugares de salida como en los de llegada.

La desigualdad al interior del conjunto de la población migrante se expresa de manera diferenciada: los indígenas, mujeres, discapacitados, jornaleros agrícolas, en tránsito, indocumentados o en situación migratoria irregular, entre otros, son grupos de migrantes que viven situaciones de exclusión social que se expresa de diferentes formas.

En sus países de origen, la población rural registra, además de los mayores índices de pobreza, los rezagos más amplios en materia educativa y de capacitación para el trabajo, lo que los convierte en la llamada mano de obra barata para insertarse en el trabajo informal de los lugares de llegada.

En los últimos cinco años, los nacionales de Guatemala, Honduras y El Salvador constituyeron entre $91 \%$ y $93 \%$ del total de los eventos de personas retenidas por las autoridades migratorias de México. De los retenidos por las autoridades de Estados Unidos en la zona fronteriza con México, esas nacionalidades representaron entre el $84 \%$ y $91 \%$ de los no mexicanos (ITAM, 2014).

De acuerdo con las Encuestas sobre Migración en la Frontera Sur de México (EMIF-SUR), del 2009 al 2014 los migrantes centroamericanos deportados por las autoridades migratorias mexicanas, suman 412, 993 (Gráfico № 1).

\section{Gráfico $\mathrm{N}^{\circ} 1$. Migrantes centroamericanos deportados} por autoridades migratorias

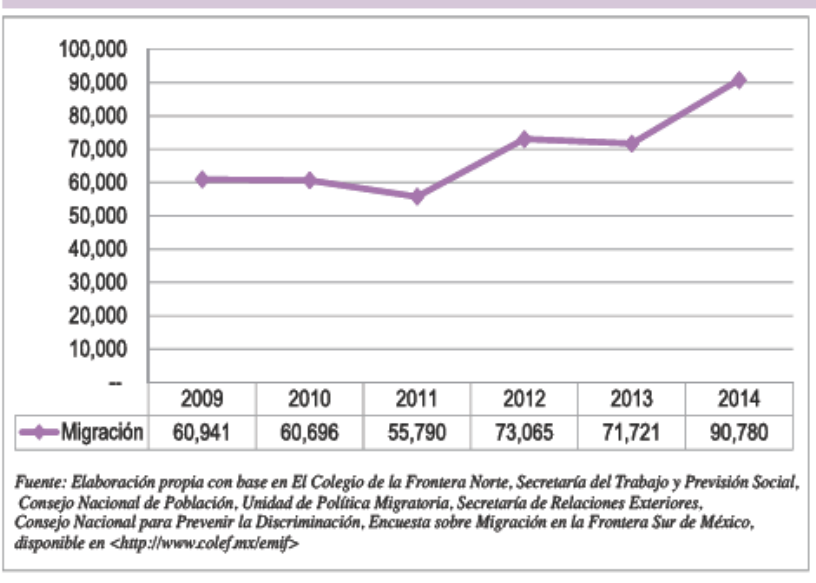

Cada año se intensifica el número de migrantes deportados por las autoridades mexicanas, lo que significa que también aumenta el número de centroamericanos que cruzan la frontera sur de México, pero muchos logran quedarse en alguna zona del país de manera indocumentada. Cada año llegan al cerca de 150,000 centroamericanos, siendo su zona de tránsito estados como: Chiapas, Campeche, Tabasco, Quintana Roo, Oaxaca y Veracruz. 
El alfabetismo y el nivel de instrucción de estos migrantes es determinante al momento de ocuparse en alguna actividad económica. Del $100 \%$ que representa la cantidad de migrantes por año, en promedio el $90 \%$ sabe leer y escribir; sin embargo, en su mayoría no tienen la instrucción básica terminada.

\section{Gráfico $\mathrm{N}^{\circ} 2$. Condición de alfabetismo de los migrantes} centroamericanos

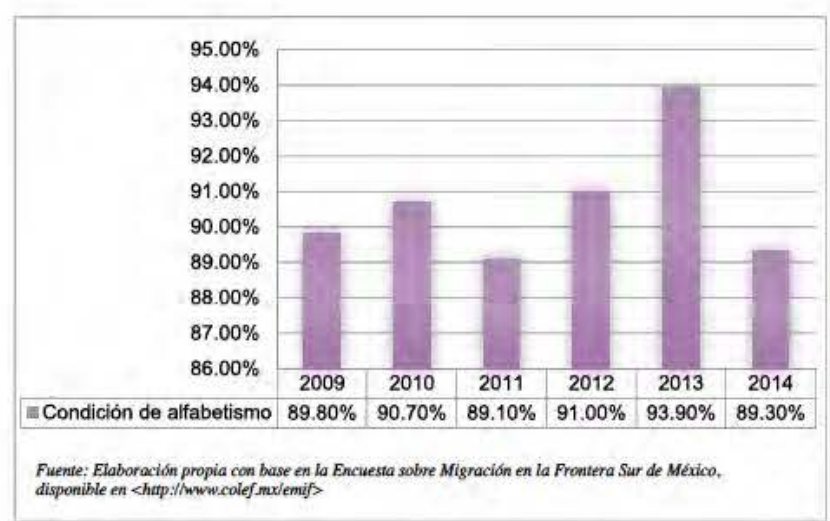

Los migrantes que se quedaron a trabajar en México, de 2009 a 2014, suman los 236,924. En promedio para los seis años de estudio, 118,234 se insertaron en el sector agropecuario (50\%); 50,930 en el sector de la construcción (21\%); 20, 930 en el sector servicios (9\%) 20,037 en el de manufactura ( $8 \%$ ); en comercio se desempeñaron 13,294 $(6 \%)$ y el resto en actividades como el transporte y los servicios domésticos y servicios diversos (Cuadro $\mathrm{N}^{\circ} 1$ ).

\begin{tabular}{|c|c|c|c|c|c|c|}
\hline Año & 2009 & 2010 & 2011 & 2012 & 2013 & 2014 \\
\hline $\begin{array}{l}\text { Población que } \\
\text { trabajó en el lugar } \\
\text { de residencia }\end{array}$ & 32,600 & 36,207 & 33,080 & 43,892 & 46,602 & 44,5 \\
\hline \multicolumn{7}{|c|}{ Sector de actividad en el que se desempeî́ } \\
\hline Agropecuario & 13,431 & 16,464 & 17,070 & 24,778 & 24,260 & 22,231 \\
\hline Manufactura & 4,305 & 3,212 & 2,114 & 2,434 & 3,497 & 4,475 \\
\hline Construcción & 8,322 & 8,586 & 7,710 & 9,053 & 9,294 & 7,965 \\
\hline Comercio & 2,273 & 2,040 & 1,729 & 1,716 & 2320 & 3,216 \\
\hline Transporte & 1,100 & 2,026 & 953 & 1,054 & 1,600 & 1,797 \\
\hline $\begin{array}{l}\text { Servicios } \\
\text { domésticos }\end{array}$ & 565 & 715 & 750 & 718 & 845 & 1,292 \\
\hline Servicios diversos & 2,606 & 3,160 & 2,740 & 4,069 & 4,786 & 3,569 \\
\hline
\end{tabular}

Fuente: Elaboración propia con base en la Encuesta sobre Migración en la Frontera Sur de México, disponible en <http://www.colef mx/emif>
De acuerdo con la Encuesta Nacional sobre Discriminación en México (ENADIS, 2010) que diseña, aplica y analiza el Consejo Nacional para prevenir la Discriminación (CONAPRED), de los migrantes encuestados, seis de cada diez consideran que en México se respetan poco sus derechos, mientras que uno de cada diez, manifiesta que sus derechos no se respetan nada ${ }^{3}$.

Las respuestas de los migrantes no son arbitrarias, pues las condiciones en que se encuentran son, generalmente, el desempleo, la discriminación y la inseguridad. De los encuestados, el $61 \%$ considera que son éstas las principales problemáticas a las que se enfrentan (ENADIS, 2010).

En atención a la situación de los migrantes en tránsito, la REDODEM exhorta a las autoridades $\mathrm{a}^{4}$ :

- Implementar una política migratoria con apego y acceso a los derechos humanos (salud, educación, trabajo, etc.) según los compromisos adquiridos en la firma de tratados internacionales, por el estado mexicano.

- Investigar, sancionar y reparar el daño derivado de los delitos cometidos por autoridades y particulares.

- Brindar información pertinente y reconocimiento de la condición de refugiado a migrantes que salen de sus países por causa de la violencia.

- Los gobiernos de Centroamérica, avanzar en una agenda de trabajo que atienda las causas estructurales por las que salen sus conciudadanos.

- Trabajar en conjunto con la sociedad, en la construcción de una cultura de hospitalidad y solidaridad que tenga como centro los sujetos humanos.

Dada la compleja relación que se presenta con la migración, hoy más que nunca los países a nivel mundial se encuentran obligados a generar políticas migratorias que permitan la convivencia de los diferentes grupos poblacionales, pues este fenómeno será sin duda central en el siglo XXI, debido a la cantidad de desplazamiento que hoy se presenta en el mundo de acuerdo a la Clasificación que realiza el Banco Mundial en los 20 corredores migratorios. Uno de los principales indicadores que potencializa al fenómeno es que es multicausal, lo cual implica que condiciones ambientales, políticas, violentas, inseguridad, laboral, profesional, etcétera, será un motivo de desplazamiento.

3 La ENADIS sólo menciona que se aplicó el cuestionario individual a personas migrantes documentadas e indocumentadas, pero no especíica el número de instrumentos aplicados.

4 Servicio Jesuita a Migrantes (2015), "Migración en tránsito por México: Rostro de una crisis humanitaria internacional", disponible en < http:/www.sjmmexico.org mx/migracion-en-transito-por-mexico-rostro-de-una-crisis-humanitaria-internacional/> 
3.3 De Centroamérica a Oaxaca, ¿migración de tránsito?

Oaxaca es una entidad ubicada al Sur-sureste de la República Mexicana, sus características son paradójicas, pues mientras por un lado destaca por su riqueza cultural, natural y gastronómica; por el otro, lo hace por los grados de pobreza, marginación y desatención a sus grupos indígenas. Esta situación provoca que los habitantes-en grupo o de manera individual- busquen oportunidades de sobrevivencia, aumentando con ello la intensidad migratoria. Oaxaca ocupa el cuarto lugar a nivel nacional de desplazamiento al interior de México y a los Estados Unidos.

En 2012, 2,436,000 individuos se encontraba en pobreza, de esta cantidad, $1,518,000$ presentaba pobreza moderada y 916,000 miles estaban en pobreza extrema (CONEVAL, 2012). Las cifras anteriores muestran que la pobreza es uno de los principales factores que propician la emigración hacia el norte del país y del continente.

Además de ser un estado expulsor de migrantes, Oaxaca se ubica como un lugar que recibe centroamericanos que cruzan a México con la esperanza de llegar a Estados Unidos de América y muchas veces logran establecerse en territorio oaxaqueño, desdibujando la migración de tránsito.

La geopolítica del estado lo ubica como uno de los más importantes del pais, ya que junto con Chiapas, Campeche, Tabasco y Veracruz, permite el paso de cientos de miles de personas provenientes de Centroamérica, al limitar con el Océano Pacífico (Mapa №1).

\section{Mapa $\mathrm{N}^{\circ} 1$. Ubicación geopolítica de Oaxaca}

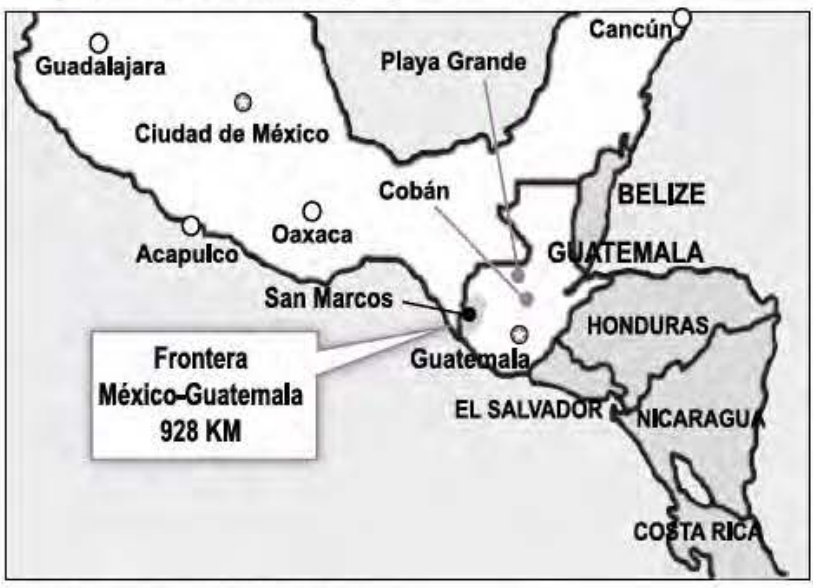

Fuente: Retomado del blog Del Sur al Norte, ubicado on

chtp:l/delsurainorter, blogspot mx/2011/10/fronteras-mexicanas htmis

No existen datos oficiales de cuántos migrantes provenientes de Centroamérica ingresan al país por Oaxaca, pero de acuerdo con datos de la Encuesta de Migrantes de la Frontera SUR (EMIF-SUR), del 2012 al
2015, el número de migrantes deportados por autoridades mexicanas, según entidad federativa de mayor tiempo de estancia, ha sido variante (Gráfico $\mathrm{N}^{\circ} 3$ ).

Gráfico $\mathrm{N}^{\circ}$ 3. Total de migrantes en Oaxaca, deportados por autoridades mexicanas

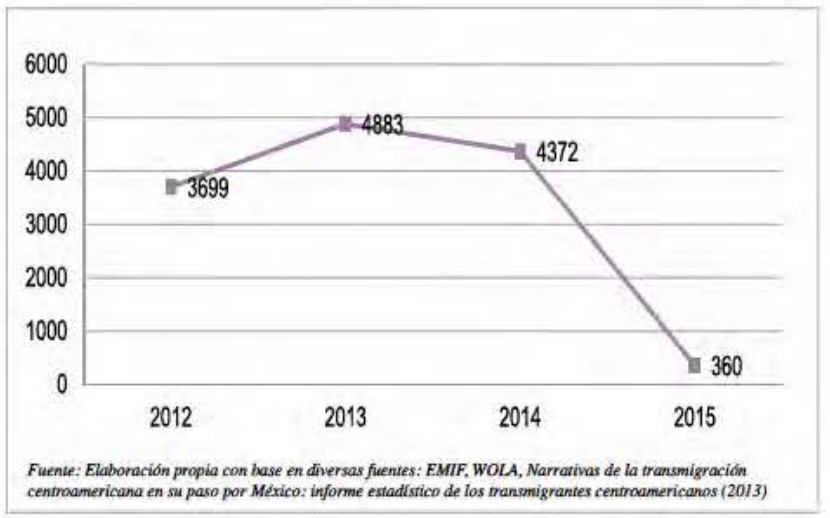

De este total por año, una proporción tiene por destino México y otra, Estados Unidos. En mayor cantidad, los migrantes desean llegar al norte del continente americano, pero por las circunstancias de paso, la falta de dinero y otros factores, se quedan en tierras mexicanas, en este caso, oaxaqueñas, con la intención de trabajar un tiempo, ahorrar y desplazarse a su destino final (Cuadro $\mathrm{N}^{\circ} 2$ ).

Cuadro $\mathrm{N}^{\circ}$ 2. Migrantes centroamericanos deportados por las autoridades migratorias mexicanas, según país de destino final

\begin{tabular}{|l|c|c|c|}
\hline \multicolumn{1}{|c|}{ Migrantes } & 2012 & 2013 & 2014 \\
\hline $\begin{array}{l}\text { Total Oaxaca con destino } \\
\text { México }\end{array}$ & 1,108 & 1,654 & 1,461 \\
\hline $\begin{array}{l}\text { Total Oaxaca con destino } \\
\text { Estados Unidos }\end{array}$ & 2,591 & 3,229 & 2,911 \\
\hline
\end{tabular}

Fuente: Encuestas sobre migración centroamericana en México 2012, 2013 y 2014

Quienes transitan por Oaxaca o residen en el estado, ya sea por periodos cortos o largos, tienen las características descritas en el apartado anterior, de los que ingresan al país, esto es: bajo nivel de instrucción educativa y su desempeño en actividades económicas como la construcción, el transporte, la manufactura y las actividades agropecuarias propias del campo.

Para 2013, de acuerdo con el Informe Estadístico sobre las características de los transmigrantes centroamericanos ${ }^{5}$, con cifras de los dos albergues que operan en el estado de Oaxaca, de 5,854 entrevistados, 2,271 dijeron dedicarse al sector económico terciario; el resto, se desarrolla económicamente en el sector primario y en la informalidad (Gráfico $\mathrm{N}^{\circ} 4$ ). 
Gráfico $\mathrm{N}^{\circ} 4$. Ocupación de los migrantes centroamericanos

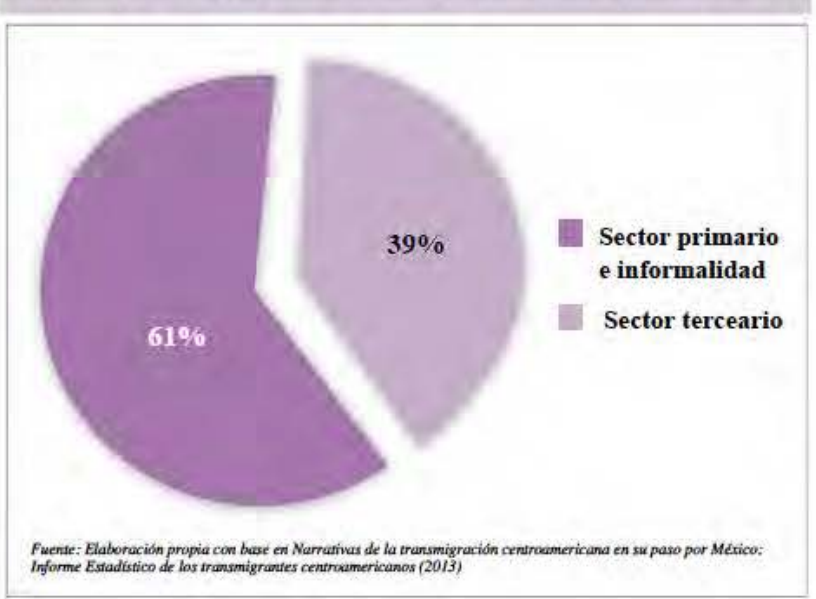

Los migrantes que se quedan en Oaxaca, incluso en el Istmo de Tehuantepec, han logrado constituir una región migratoria. Por este término - región migratoria-, se entiende: "espacio físico y simbólico estructurado a partir de la identidad de sus pobladores, quienes buscan acceder al desarrollo a través del intercambio de bienes y servicios, dentro de un patrón de alta movilidad territorial, en la que diversos espacios sociales y geográficos se integran en un solo espacio común, en una lógica de mercados globales y competitivos" (Reyes, 2010).

Estos migrantes buscan acceder al desarrollo, pero ven que las condiciones de vida en la que se encuentran inmersos son similares a las que tenían en sus países de origen; que si allá eran los 'olvidados' del Estado, aquí también lo son, y no sólo del aparato estatal, sino de parte de la población nativa de Oaxaca.

A los centroamericanos que están en territorio oaxaqueño, los une el sentido de no pertenencia a la cultura del lugar de tránsito o residencia, pero también el sentimiento de inconformidad por la restricción a sus derechos humanos, pues no tienen las garantías de seguridad y protección a su integridad en el cruce, traslado y estancia en la región sur-sureste de México.

Aunque todavía no es clara la organización de centroamericanos en las regiones de México y de Oaxaca, son algunas organizaciones civiles y religiosas las que han entrelazado a los migrantes, quienes ya no continúan su camino hacia el norte, sino que se establecen en la zona del Istmo y en la de Valles Centrales, principalmente.

Hay que destacar que la iglesia católica juega un papel importante en la visibilización y protección al migrante proveniente de Centroamérica. En ciudad Ixtepec, en el Istmo de Tehuantepec, se encuentra el albergue "Hermanos en el Camino" y en la capital del estado, el "Centro de Orientación al Migrante de Oaxaca"; el primero, a cargo del Presbitero Alejandro Solalinde y, el segundo, al frente del sacerdote Fernando Cruz.

Las ciudades donde se ubican los albergues son importantes geopolíticamente. Ciudad Ixtepec conecta el Océano Pacífico, el Golfo de México y la frontera sur del país, ha sido escogida por la delincuencia organizada para ser su centro de operaciones; es uno de los sitios más codiciados para obtener enormes ganancias lucrando con los migrantes, de todas las formas posibles ${ }^{6}$.

El trabajo de "Hermanos en el camino", se despliega en el sentido de disminuir estas condiciones adversas al migrante, pues ante todo debe garantizarse la protección a sus derechos humanos, entendiendo que "la relación entre migración y derechos humanos está presente en todo el ciclo migratorio: en las motivaciones para su salida del país de origen, durante su tránsito y al llegar a su destino" (Artola, 2008).

La apropiación del espacio público es una de las características de esta incipiente región migratoria centroamericana en Oaxaca, ya que en las calles de Ciudad Ixtepec los migrantes comienzan a manifestarse para exigir que se respeten sus derechos y, además, que se atiendan las denuncias que interponen ante la institución correspondiente, debido a los delitos de los que son víctimas en el Estado.

Los migrantes son acompañados por el sacerdote Solalinde y activistas que apoyan la causa, cuando salen en marcha, caravana o cualquier otro tipo de protesta más allá de las instancias gubernamentales estatales ${ }^{7}$. Son estos actores de apoyo a los migrantes los que impulsan la conformación de la región migratoria, pues en este mundo globalizado, las interconexiones entre nacionalidades distintas en un mismo espacio físico y en la misma temporalidad, tienen que estar sostenidas por agentes que conozcan el espacio y a los miembros de esa región migratoria.

Para los migrantes que se desplazan con familias completas, de acuerdo a un diagnóstico realizado por Reyes (2003) sobre Educación Básica sin Fronteras se detectó que en el estado de Oaxaca los niños y niñas centroamericanos son tratados en condiciones de desigualdad y se relacionan con el mismo trato que reciben los grupos étnicos en la escuelas de la ciudad. No se considera su condición cultural para implementar acciones en beneficio de un aprovechamiento escolar y son discriminados en las aulas por los miembros de la comunidad estudiantil.

\footnotetext{
Informe que elabora la REDODEM

Albergue Hermanos en el Camino, disponible en < http: $/ / w w w h e r m a n o s e n e l c a m i n o . o r g />$

En abril de 2015 , aproximadamente 200 centroamericanos y activistas partió de ciudad Ixtepec, Oaxaca, con rumbo a la Ciudad de México, plara pedir mayor seguridad en su ruta hacia la frontera norte de México
} 
Por lo que por el corto tiempo que logran durar en las escuelas en su tránsito por Oaxaca, algunos reprueban el ciclo escolar, otros desertan en el ciclo escolar, lo cual da pauta para pensar en trámites administrativos en el ámbito educativo y la articulación para seguir al estudiante que logra inscribirse.

\subsection{Problemáticas a las que se enfrentan.}

La violencia física es uno de los principales problemas a los que se enfrentan los migrantes al cruzar el territorio oaxaqueño, debido a que diferentes grupos delictivos y también autoridades municipales o estatales, ven en ellos un sector desprotegido; entre los principales delitos de los que son víctimas, están los siguientes: extorsión, asalto, abuso de autoridad, lesiones, desaparición y tráfico de personas, robo, amenazas, tentativa de extorsión, secuestro, homicidio calificativo, violencia intrafamiliar, violación, privación ilegal y robo con violencia. Por la condición de vulnerabilidad en la que se encuentran, y por temor a ser deportados, no denuncian estos delitos. Para el año 2013, sólo se presentaron ante la Procuraduría General de Justicia de Oaxaca, 104 denuncias por los delitos antes mencionados ${ }^{8}$.

Quienes trafican con migrantes no se conforman con la ruta del Istmo de Tehuantepec, sino que han abierto nuevas rutas en la Costa, la Sierra Mixe, la Mixteca y la Cañada. La necesidad de los centroamericanos les lleva a buscar más rutas, pero en todas la violencia impera.

Desafortunadamente las mujeres son las principales víctimas de los grupos delictivos, ya que no sufren únicamente violaciones físicas sino que también son cooptadas por el negocio de la trata de blancas. En el istmo de Tehuantepec y en las calles de la Ciudad de Oaxaca y zona conurbada, es posible distinguir a mujeres migrantes provenientes de Centroamérica que se dedican a trabajar en centros nocturnos o en las calles, sufriendo explotación, violencia física y psicológica. Pocos han sido los casos en donde son rescatadas por las autoridades estatales o municipales, también pocos son los casos que se denuncian, por ejemplo en 2013 sólo cinco denuncias fueron recibidas por la PGJE.

El hecho de que sean migrantes no significa que pueden ser vulnerados en sus derechos. A la par de la discriminación y criminalización de la vida del centroamericano en Oaxaca, se desarrollan intolerancia, xenofobia y exclusión social. Ante la situación antes señalada, el Comité de los Trabajadores Migrantes (CMW) hace las siguientes recomendaciones concretas a los Estados Partes"
- Promulgar leyes y otras reformas para eliminar todas las formas de discriminación contra los migrantes;

- Fortalecer la aplicación de la ley y de la justicia penal a la xenofobia y la violencia y permitir a los inmigrantes acceder a la justicia;

- Crear campañas para poner fin a los mensajes públicos negativos e inexactos y promover la tolerancia y el respeto a los migrantes;

- Recopilar y difundir datos exactos sobre la discriminación y sobre las contribuciones positivas que los migrantes hacen al desarrollo tanto de sus países de acogida como de las comunidades de origen.

Estas recomendaciones en el marco de la Región Migratoria, cobran mayor relevancia, pues los migrantes tienen derecho de tránsito como personas que son, ya que los Estados no pueden frenar las aspiraciones de los individuos cuando no han sido capaces de generar políticas públicas que les permitan a la población tener cubiertas las necesidades básicas que tienen como seres humanos, por lo que las fronteras cada vez se vuelven más borrosas y porozas, generando nuevas reconfiguraciones territoriales en las cuales, las fronteras físicas se desdibujan para formar regiones en el marco de identidades, expresiones sociales y culturales que cada grupo de migrantes lleva implícita en su proceso de migración en el tiempo y el espacio.

\section{Conclusiones}

La migración internacional sigue siendo un tema pendiente en la agenda de los países expulsores y receptores de migrantes. Conforme pasa el tiempo, la migración centroamericana se ha intensificado y con ello las violaciones a sus derechos humanos; la autoridad federal y estatal aún no logran detener los grandes problemas por los cuales atraviesan los migrantes, los cuales van desde robo de pertenencias hasta el secuestro (principalmente por grupos delictivos); en el caso de las mujeres son utilizadas para la trata de personas y que son trasladadas a diferentes puntos del estado para ser prostituidas en los centros nocturnos o en las calles.

Por las situaciones adversas que viven han logrado constituir redes de identidad entre ellos y con esto, empiezan a conformar su propia región migratoria, apoyados por actores de la sociedad civil y de la Iglesia.

Su región migratoria estaría compuesta, entonces, por los elementos siguientes:

8 Respuesta al Oficio número PGJE/DAJ/U.E/167/2015 realizada por el Director de Asuntos Jurídicos y titular de la Procuraduría General de Justicia del Estado al Fiscal de Atención al Migrante. Ubicada en: <https://es.scribd.com/doc/270754920/Oaxaca-2013>

9 ONU, 2014, "La criminalización no es una solución para la migración irregular, Comité de la ONU", disponible en <http://www.oacnudh.org/?p=3673>. 
- Identidad de los miembros a su llegada al lugar de residencia: se encuentran desfavorecidos socialmente en el país de origen <condiciones socioeconómicas, acceso a servicios y a instrucción académica>.

- Identidad de los miembros en el lugar de residencia: violentados en sus derechos humanos y desfavorecidos laboralmente.

- Nivel de desarrollo económico del lugar de salida y de llegada, lo cual no favorece su calidad de vida.

- Actores que rodean a los migrantes en el nuevo espacio temporal en el que se desenvuelven: los positivos Organizaciones de la Sociedad Civil e Iglesia y sus albergues- y los negativos -traficantes, asaltantes, autoridades policiacas-.

- Medios de comunicación que permiten integrar a los que se encuentran en desplazamiento en cualquier contexto mexicano.

- Procesos formativos relacionados con la educación del grupo de migrantes y sus aprendizajes en el tiempo migratorio y espacios de convivencia.

Es Oaxaca una zona de alta movilidad migratoria, tanto de salida como de llegada, pero hacen falta acciones efectivas, políticas públicas que atiendan las problemáticas de los migrantes, que en el caso de los centroamericanos están conformando en el estado su región migratoria, caso contrario a lo que hacen los oaxaqueños residentes en otro espacio, pues es en éste donde la construyen, donde trasladan su identidad.

Por último, la región migratoria conformada desde el grupo de migrantes centroamericanos, permite constituirse en un grupo que se articula más allá de sus fronteras en las cuales desde sus prácticas sociales, las poblaciones en movimientos, desafían a las políticas públicas generada por los Estados, pues dada la dinámica de los flujos migratorios, hoy los Estados han sido rebasados y se necesita mirar más allá del territorio físico que constituye a su entidad, es necesario dar cuenta que se requieren de acciones de tipo regional, que permita generar acciones de política pública en beneficio de estos grupos que se constituyen como vulnerables al no ser atendidos por las diferentes autoridades por donde transitan y por donde los grupos delincuenciales cada día se articulan y crecen para atacar a la población migrante.

\section{Bibliografía}

- Artola, Juan. (2008). Las migraciones en la agenda internacional, en Villafuerte, Daniel y María del Carmen García, Migraciones en el sur de México y Centroamérica, (pp. 17-47). México: UNICACHPORRÚA.
- CONEVAL. (2012). Informe anual sobre la situación de pobreza y rezago social. México: SEDESOL.

- Encuesta Nacional sobre Discriminación en México. (2010). México: Consejo Nacional para Prevenir la Discriminación.

- Encuesta sobre Migración en la Frontera Sur de México (2009-2014), El Colegio de la Frontera Norte, Secretaría del Trabajo y Previsión Social, Consejo Nacional de Población, Unidad de Política Migratoria, Secretaría de Relaciones Exteriores, Consejo Nacional para Prevenir la Discriminación, recuperado de <http://www.colef. $\mathrm{mx} / \mathrm{emif}>$

- Escobar, Carolina. (2008). Los pequeños pasos en un camino minado: Migración, niñez y juventud en Centroamérica y el sur de México. Guatemala: Consejería en Proyectos.

- ITAM (2014), Migración centroamericana en tránsito por México hacia Estados Unidos: Diagnóstico y recomendaciones. Hacia una visión integral, regional y de responsabilidad compartida. México: ITAM.

- Morales, Abelardo. (2008). Migraciones, regionalismo y ciudadanía en Centroamérica, en Villafuerte, Daniel y María del Carmen García. Migraciones en el sur de México y Centroamérica (pp. 49-75). México: UNICACH-PORRÚA.

- ONU. (2009). Promoción y protección de todos los derechos humanos, civiles, políticos, económicos, sociales y culturales, incluido el derecho al desarrollo. $<$ Adición al Informe del Relator Especial sobre los derechos humanos de los migrantes, Sr. Jorge Bustamante $>$, recuperado de <http://www.acnur.org/t3/ uploads/media/COI_2587.pdf?view $=1>$ G.

- ReddeDocumentación de las Organizaciones Defensoras de Migrantes (2013a). Narrativas de la transmigración centroamericana en su paso por México. Informe sobre las violaciones a derechos humanos y delitos cometidos a transmigrantes centroamericanos. México: Servicio Jesuita de Migrantes, Albergue Hermanos en el Camino, La 72, Centro de Orientación del Migrante de Oaxaca, Albergue Decanal Guadalupano, FM4 Paso Libre, Centro de Derechos Humanos Juan Gerardi, Casa del Migrante San Carlos Borromeo, recuperado de $<$ http://www.fm4pasolibre.org/redodem/narrativas_de la_transmigracion_centroame ricana_redodem_vol1_ caracteristicas.pdf $>$

- Reyes de la Cruz. (2003). Diagnóstico sobre Educación Básica sin Fronteras. (Informe técnico). México: IISUABJO/IEEPO.

- Reyes de la Cruz, Virginia. (2010). Región Migratoria. La construcción social de los jornaleros agrícolas migrantes. México; Miguel Ángel Porrúa/UABJO/ PROMEP. 